\title{
$\mathrm{S}$ \\ Turismo e Sociedade Revista I UFPR
}

\section{Turismo na cidade do Rio de Janeiro e a motivação neoliberal no desenvolvimento da acessibilidade universal}

Tourism in the city of Rio de Janeiro and the neoliberal motivation in the universal accessibility development

Bianca dos Santos Magalhães ${ }^{1}$ Adriana Soares de Schueler²

RESUMO: As políticas públicas para pessoas com deficiência estão descritas na Lei Federal Brasileira n 13.146/2015, também conhecida como Estatuto da Pessoa com Deficiência, e que visa assegurar e promover a igualdade visando inclusão social e cidadania, principal amparo jurídico nacional para deficientes. Ademais, como as pessoas com deficiências são uma pequena parcela da população, muitas vezes os destinos turísticos não apresentam meios para desfrutarem a cidade e se deparam com limitações no espaço que dificultam seu deslocamento, bem como o acesso a bens e serviços disponíveis. No entanto, ao tomar como referência a atividade turística para este público, alguns embargos em relação a infraestrutura dos locais a serem visitados podem ser encontrados. Com isso, pretendese analisar a estruturação dos principais atrativos turísticos da

\footnotetext{
1 Mestrado em Desenvolvimento Territorial e Políticas Públicas pela Universidade Federal Rural do Rio de Janeiro (UFRRJ). Graduação em Turismo pela UFRRJ. E-mail: biamagalhaes.tur@gmail.com 2 Doutorado em Engenharia Civil pela Universidade Federal do Rio de Janeiro (UFRJ). Mestrado em Engenharia Civil pela Universidade Federal Fluminense (UFF). Graduação em Arquitetura e Urbanismo pela UFF. Professora associada do Departamento de Arquitetura e Urbanismo (DAU) e do Programa de Pós-graduação em Desenvolvimento Territorial e Políticas Públicas da Universidade Federal Rural do Rio de Janeiro (UFRRJ). E-mail: schueler.a@gmail.com
} 
cidade do Rio de Janeiro para pessoas com deficiência, tendo em vista a tendência das medidas estatais para atendimento do mercado. Foi realizada uma pesquisa qualitativa, com pesquisa documental e observações em campo. Para este estudo adotou-se como referência a pessoa com deficiência motora, refletindo sobre os impactos das políticas econômicas de cunho neoliberal e as premissas encontradas nas leis de apoio à pessoa com deficiência. É ressaltada a importância do desenvolvimento social pela acessibilidade universal, porém mostrando o quanto o modelo neoliberal influencia no modo como a infraestrutura para pessoas com deficiência é tratada. Foi observado que há necessidade de ajuste da continuidade nas rotas para acessibilidade e investimento na melhoria das alternativas já existentes de acessibilidade universal.

Palavras-chave:Turismo; Acessibilidade Universal; Rio de Janeiro; Neoliberalismo

ABSTRACT: Public policies for people with disabilities are described in the Brazilian Federal Law 13.146/2015, also known as the Statute for People with Disabilities, which aims to ensure and promote equality aiming at social inclusion and citizenship, the main national legal support for the disabled. In addition, as people with disabilities are a small part of the population, touristic destinations often do not have the means for these people to enjoy the city where they face limitations in space which make difficult their movement, as well as the access to available services. However, taking tourism as a reference for this specific audience, some embargoes regarding the infrastructure of the touristic places can be found. Then, this study intended to analyze the structuring of the main tourist attractions in the city of Rio de Janeiro for people with disabilities, considering the trend of state measures to serve the tourism sector. A qualitative research was carried out, with document analysis and observations in loco. For this paper, people with motor disabilities were adopted as reference, reflecting on the impacts of neoliberal economic policies and the premises found in the laws which support people with disabilities. The importance of the social development is emphasized through universal accessibility, but showing how much the neoliberal model influences the way which infrastructure for people with disabilities is treated. It was also observed that there is a need to adjust the continuity in the routes for accessibility and investment in order to improve the existing alternatives of universal accessibility.

Keywords: Tourism; Universal Accessibility; Rio de Janeiro; Neoliberalism 


\section{INTRODUÇÃO}

No Brasil as políticas públicas para pessoas com deficiência são constituídas por uma legislação que discorre sobre os direitos e as ações integradoras da sociedade civil ou estatal para com estes. O esquecimento às necessidades deste público se desdobrou por muito tempo, no entanto, no país, as leis se tornaram mais assertivas e colaborativas no trato da pessoa com deficiência.

A Lei Federal, $n^{\circ} 13.146 / 2015$, conhecida como Lei Brasileira da Pessoa com Deficiência assegura e promove o exercício dos direitos das pessoas com deficiência, define conceitos, critérios e normas.

A legislação turística estabelece parâmetros de acessibilidade universal nos destinos através do documento intitulado Plano Nacional de Turismo (PNT), elaborado pela equipe técnica do Ministério do Turismo, reforçando a importância de estruturar os locais a fim de receber a pessoa com deficiência com uma logística facilitada. $O$ PNT atual (2018-2022), de forma direta, determina que:

\footnotetext{
Estados e municípios, individualmente ou em parceria com o Governo Federal, têm o compromisso de apoiar os investimentos de infraestrutura e sinalização turística, para permitir a expansão da atividade e a melhoria da qualidade dos destinos e produtos das regiões turísticas brasileiras, com base nos princípios da sustentabilidade, garantindo acessibilidade às pessoas com deficiência e mobilidade reduzida" (BRASIL, 2019a, p. 98).
}

É pertinente discutir a vivência da pessoa com deficiência no âmbito do turismo porque, da mesma forma que a lei apresenta direitos assegurados para essas pessoas e transpõe a responsabilidade para as iniciativas privadas, a compreensão se torna melhor ao partir do pressuposto básico que o turismo é uma atividade de bens e serviços.

Se os bens e serviços não são oferecidos a uma demanda específica, cabe uma análise dos motivos e, principalmente, cabe uma colocação a respeito da validade do modelo neoliberal enquanto elemento que fomenta a privatização, mas apenas se dedica à projetos de retorno financeiro seguro e certeiro. O modelo econômico neoliberal que se evidenciou mais no período político do Governo FHC no Brasil se caracterizou por um estímulo ao incentivo capital dos grupos econômicos e sua consolidação em solo nacional, de modo a restringir os poderes estatais, também a diminuição de empresas públicas (COUTO, 2003). Cortar direitos reduzindo os serviços públicos, tocar adiante a política de ajuste fiscal, que viabiliza a remuneração do capital financeiro, e abrir novas áreas para a acumulação capitalista (BOITO, 2004).

Porém, ao abordar qualquer atividade econômica, é importante pensar em situações práticas que permitam refletir sobre as motivações que regem alguns processos vistos no espaço. No caso da estruturação do espaço para a pessoa com deficiência em locais turísticos, tal estruturação está embasada num aporte legal, de caráter inclusivo. Com o fomento financeiro induzido pela atividade turística. 
Como exemplo, estão os eventos esportivos na cidade do Rio de Janeiro (em 2014 e em 2016) foram exitosos em relação ao expressivo número de turistas que vieram para a cidade. A marca deixada pelos eventos é vista na mobilidade urbana presente na cidade que sofreu uma mudança paisagística em locais como a região portuária, por exemplo. Para realizar as obras de melhorias para as estruturas esportivas e mobilidade, recebeu investimentos privados e públicos da ordem de $R \$$ 41 bilhões somente para os Jogos Olímpicos (BRASIL, 2019). Mas os investimentos na cidade do Rio de Janeiro para atender os grandes eventos, que fomentaram o setor do turismo, os bens e serviços voltados para a pessoa com deficiência se tornam produtos para consumo desta demanda específica.

No setor turístico a viabilização e adaptação das vias públicas é uma forma que o Estado tem de manter a organização dos territórios e planejá-los para fins turísticos. Apesar de a acessibilidade citadina nem sempre visar atender as pessoas deficientes, turistas ou não, o impacto destas políticas deverá ser alcançado por meio do planejamento Estatal.

Posto isso, o artigo analisa a estruturação dos principais atrativos turísticos da cidade do Rio de Janeiro para pessoas com deficiência, tendo em vista a tendência das medidas estatais para atendimento do mercado e pretende refletir sobre o impacto das políticas econômicas neoliberais como motivador do processo de adaptação dos espaços. Parte da execução das políticas públicas conta com a colaboração de iniciativas privadas para o desenvolvimento de parâmetros de acessibilidade que vão além do alcance do poder público. Mas a mobilidade das pessoas com deficiências é impactada pelo modo como o aparato do Estado é capturado por agentes políticos com interesses capitalistas e que consideram o neoliberalismo como diretriz econômica, pela elaboração de políticas públicas que não integram as questões sociais e pelo impacto das mesmas nos espaços urbanos.

Esta pesquisa é de caráter qualitativo, pois a abordagem consistiu numa verificação da forma como a cidade do Rio de Janeiro lidou com a questão da acessibilidade universal, bem como a checagem de quais lugares foram adaptados e as motivações para esta adaptação. As informações de reportagens e a experiência da autora do presente artigo como guia de turismo atuante na cidade do Rio de Janeiro contribuíram para o desenvolvimento desta abordagem, pois por conhecer a cidade e seus locais turísticos, pôde realizar essa análise de forma detalhada. A coleta de dados utilizou também informações dos websites oficiais dos locais turísticos a serem relacionados e os atrativos turísticos listados da Riotur - Empresa de Turismo da cidade do Rio de Janeiro. A partir disso foi feita uma análise de dados que permitem verificar quantos e quais atrativos estão preparados para receber a pessoa com deficiência, como forma de inclusão dos mesmos e integração aos locais de lazer e turismo.

Assim, este artigo foi estruturado primeiramente com a compreensão da legislação vigente para promoção de cidades mais acessíveis seguida de uma reflexão sobre a teoria neoliberal no processo de aplicação dessas políticas públicas. Com a consulta a dados secundários sobre os usuários da cidade do Rio de Janeiro também 
foram descritas as dificuldades encontradas nos locais turísticos que as pessoas com deficiência ou mobilidade reduzida utilizam.

Então são avaliadas as principais atrações turísticas da cidade do Rio de Janeiro apresentando a acessibilidade para seus visitantes. Por fim, avalia-se os impactos ou o legado das obras relacionadas aos grandes eventos turísticos quanto às perspectivas de uma cidade mais inclusiva. Isso posto, apresenta-se as considerações finais e as iniciativas voltadas para pessoas com deficiência são, tão somente, visando incluí-las ou permitindo o acesso delas à cidade para serem integradas ao processo produtivo e de acumulação de capital.

\section{AMPARO LEGAL DA ACESSIBILIDADE UNIVERSAL APLICADO AO ÂMBITO DO TURISMO: IMPORTÂNCIA DAS CIDADES ACESSÍVEIS}

A Constituição Brasileira estabelece princípios gerais de direitos que favoreçam à pessoa com deficiência e mobilidade reduzida, o que busca a redução da desigualdade. Além de uma premissa constitucional, também se trata de uma medida legal, pois a lei assegura os direitos à pessoa com deficiência e descreve o lazer como importante, conforme instituído no capítulo IX, artigo 42, da Lei Federal $n^{\circ}$ 13.146, de 06 de julho de 2015, a saber:

\footnotetext{
A pessoa com deficiência tem direito à cultura, ao esporte, ao turismo e ao lazer em igualdade de oportunidades com as demais pessoas, sendo-lhe garantido o acesso: I - a bens culturais em formato acessível; II - a programas de televisão, cinema, teatro e outras atividades culturais e desportivas em formato acessível; e III - a monumentos e locais de importância cultural e a espaços que ofereçam serviços ou eventos culturais e esportivos.
}

Este estudo aborda a atividade do turismo considerando a premissa encontrada na Lei $n^{\circ} 13.146$ a respeito do lazer como motivo para viajar. Quando esta motivação por viajar ocorre se observa o aperfeiçoamento dos serviços turísticos que visam a captação e a aderência de seus serviços oferecendo à pessoa com deficiência um bem de caráter intangível, cujo retorno se reflete num bem-estar subjetivo. No entanto, para aperfeiçoar os serviços que atendem a demanda turística, é importante que as vias de acesso ao destino, bem como seu entorno e infraestrutura estejam adequadas para a pessoa com deficiência, pois o destino é o local onde as ações serão desenvolvidas.

Assim, a Lei Federal n 13.146/2015 trata dos direitos assegurados à pessoa com deficiência e institui deveres e responsabilidades que se estendem à iniciativa privada, por exemplo, quanto à reforma e construção de edificações descrita no artigo 57 da referida Lei: "As edificações públicas e privadas de uso coletivo já existentes devem garantir acessibilidade à pessoa com deficiência em todas as suas dependências e serviços, tendo como referência as normas de acessibilidade vigentes". É importante 
o destaque dado a iniciativa privada na legislação, porque permite indagar a ausência das estruturas de acessibilidade mesmo quando exigido em lei.

Além da lei descrita, existem as normas técnicas voltadas para a estruturação das vias e edificações que objetivam a acessibilidade universal. A implementação das normas técnicas está relacionada ao uso do espaço, acessibilidade e inclusão. Como exemplificação, têm-se as normas ABNT NBR 9050 que regula e define os aspectos de acessibilidade para as edificações e espaços citadinos.

No entanto, se as cidades com vocação turística ainda possuem lacunas em seu desenvolvimento cuja inclusão dos indivíduos com deficiência é apenas parcial, questiona-se o papel das políticas públicas de turismo e a real aplicabilidade dos projetos de infraestrutura que visam apenas a lucratividade em detrimento da visão humana. As cidades devem integrar e desenvolver soluções que visam o bem-estar dos cidadãos de maneira a diminuir as barreiras físicas que impedem a locomoção e o acesso das pessoas aos locais. Segundo Garcia (2008) a inserção da acessibilidade universal de forma transversal em todos os espaços, equipamentos e serviços é a chave para atingir o objetivo principal dessas políticas, que é incluir todas as pessoas, ou ao menos o maior número possível, no processo de planificação e aplicação das ações, públicas ou privadas, em temas como edificações, urbanismo, transporte, comunicação e informação.

Em relação à inclusão, é importante mencionar a análise realizada por Jan Gehl (2013) a respeito da forma física que assumiram as cidades. O autor traça um panorama entre o antes/depois das cidades. Atualmente, com o crescimento populacional e o aumento do volume de veículos, as pessoas se espremem nas calçadas e se deparam com obstáculos.

\footnotetext{
Para que uma caminhada seja confortável, inclusive quanto às distâncias e ao ritmo aceitáveis, é preciso que haja espaço para andar, sem muitas interrupções ou obstáculos. Muitas vezes estas qualidades estão presentes em áreas exclusivas para pedestres, mas são raras nas calçadas de muitas cidades. Pelo contrário, é impressionante observar quantos obstáculos e dificuldades foram incorporados à paisagem do pedestre no decorrer dos anos. Sinais de tráfego, postes de iluminação, parquímetros e todos os tipos de aparelhos de controle são sistematicamente colocados nas calçadas para não "atrapalhar a rua". Veículos estacionados sobre a calçada ou em parte dela, bicicletas mal estacionadas, anúncios e placas dispostos desordenadamente completam o quadro, onde os pedestres precisam manobrar, como esquiadores descendo uma pista de slalom, para andar e uma calçada que, já de início, é estreita demais (GEHL, 2013, p. 123).
}

Este panorama mencionado por Gehl (2013) a respeito das dificuldades que um pedestre comum passa ao se locomover pela cidade se agrava quando se trata de um deficiente visual ou motor - completo ou parcial. Questionamento que, ao ser aplicado em cidades com diversos atrativos turísticos como o Rio de Janeiro, se agrava devido a visibilidade em âmbito mundial advindo com os grandes eventos.

Um problema recorrente nas pesquisas em campo sobre acessibilidade universal 
é a questão da continuidade, ou seja, a implantação de medidas de acessibilidade universal de forma parcial, sem considerar os arredores do local onde foi implantado. Por exemplo: um edifício adaptado para cadeirantes ou deficientes visuais numa rua de pedras, paralelepípedo ou calçadas com concretos rachados. O cadeirante ou o deficiente visual precisa chegar ao edifício e passar pelos obstáculos que as vias públicas apresentam. Por isto a falta de continuidade é um problema a ser solucionado e para isso é necessário o planejamento de uma estrutura adequada que permita uma integração natural e uma percepção discreta das soluções dadas para contornar este problema.

Conforme Garcia (2008), é importante ressaltar que um bom desenho universal deve ser invisível, não ser notado. Uma entrada com rampa suave para transpor os desníveis de uma edificação é solução mais adequada do que um elevador para cadeira de rodas fixada na escada, além disso todos os usuários são beneficiados por essa solução na medida em que ninguém precisará subir os degraus. Calçadas rebaixadas, acessos quase ao mesmo nível da rua, ônibus de degraus baixos são soluções quase imperceptíveis e cuja origem foi tentar solucionar a acessibilidade das pessoas portadoras de deficiências. Em resumo, quanto mais geral e invisível a solução, melhor. A acessibilidade universal, quando está bem resolvida, não é notada e beneficia a todos (GARCIA, 2008).

No turismo a acessibilidade universal possui relação com a hospitalidade, pois aos turistas que necessitam utilizar os recursos de acessibilidade universal se sentem integrados ao perceberem que a eliminação das barreiras de locomoção foi priorizada no local e as dificuldades foram minimizadas. Esta locomoção iguala a condição da pessoa com deficiência às demais pessoas que se locomovem normalmente e permite que o deficiente visual ou motor perceba o local e dele obtenha experiências positivas.

\section{MOTIVAÇÃO NEOLIBERAL NO DESENVOLVIMENTO DA ACESSIBILIDADE UNIVERSAL}

Atualmente, a doutrina neoliberal ganhou destaque na política econômica brasileira, na qual se observa a acelerada dominação do capital financeiro sobre a economia do país que, devido as suas configurações atuais em nossa sociedade, alguns autores preferem adotar o termo ultraliberal1 (RIBEIRO, 2020). Ao buscar nas bases teóricas da economia a explicação para o neoliberalismo, vale pontuar que é uma revisão da escola clássica, que tem Adam Smith e David Ricardo seus principais expoentes, e se contrapõem à teoria de John Maynard Keynes que pregava acentuada intervenção estatal.

O neoliberalismo, que tem em Friedrick Hayek seu principal teórico, propunha que o Estado fosse responsável pela infraestrutura produtiva e regulasse a economia

1 Mais sobre a denominação citada pode ser consultado em Ribeiro (2020, p. 01). 
caso apresentasse distorções, mantendo mínima sua atuação. Ainda são característica dessa teoria a privatização das empresas estatais, redução da cobrança de impostos, protecionismo econômico e livre circulação de capitais (MOTTA BRANDAO, 2013)2.

Por um lado, há políticas públicas que estipulam parâmetros de cumprimento às premissas de acessibilidade universal para turistas com deficiência e mobilidade reduzida. Por outro lado, são encontradas lacunas na acessibilidade universal local e a ineficiência de serviços de acessibilidade que assistam a pessoa com deficiência. $A$ pessoa com deficiência é excluída da integração à vida na cidade e atividades como o turismo se tornam um fardo, para estes indivíduos, devido as muitas limitações encontradas nos destinos e atrativos. Embora a disponibilidade de informações ao público em geral tenha aumentado nos últimos anos, estas ainda são insuficientes, não se obtendo mudanças efetivas da sociedade, verificando-se que as situações de exclusão ainda são frequentes seja no trabalho, no comércio, nas viagens, no restaurante, entre outros lugares (MENDES, 2008)

Sobre o papel do governo na atividade turística, Fernandes e Coelho (2011, p. 62) afirmam que:

\footnotetext{
[...] Devido à própria natureza da atividade turística, um movimento de massa com impactos econômicos e sociais, com amplos encadeamentos em outras atividades econômicas, desenvolvimento regional e comércio exterior, é natural admitir que o governo tem algumas funções nesta área, em atuação conjunta com o setor privado. Sem dúvidas, existem custos para a autoridade pública, um dever para fazer como dono da casa que recebe convidados que estão pagando e recebendo benefícios de receitas tributárias derivadas dos gastos dos visitantes. Logo, parece óbvio que em países desenvolvidos e em desenvolvimento existe um papel importante para o Estado e os governos locais.
}

Visando promover uma cidade mais equânime, cabe a iniciativa estatal, por meio das políticas públicas, a inclusão da pessoa com deficiência, uma vez que o mercado não irá suprir as necessidades destes indivíduos. Mas ainda assim, o capital se apropria das demandas necessárias para a inclusão destes indivíduos visando lucro, ou seja, a pessoa com deficiência se torna um consumidor em potencial. Esse período neoliberal, marcado pela diminuição da interferência do Estado nos distintos espectros da vida da sociedade reafirmou o direito de propriedade e os direitos do consumidor, que se sobrepuseram aos direitos sociais dos cidadãos, tornando o lazer e turismo acessível apenas para uma parcela da população (BORGES, 2011).

Para alcançar cidades mais acessíveis é necessário que as vias urbanas e os meios de transporte se adequem ao modelo inclusivo, apesar da dificuldade na promoção de tais aspectos. Garcia (2008, p. 62), observou que:

2 Para compreender melhor os conceitos e noções de projeto neoliberal, modelo neoliberal e atividade neoliberal no Brasil, ver FILGUEIRAS (2006). 
A maioria das pessoas portadoras de deficiência, idosos, mulheres grávidas, quer seja por razões econômicas ou porque não desejam ter um automóvel particular, têm uma grande dificuldade em deslocar-se nas grandes cidades. A cidade está repleta de barreiras que dificultam a vida daqueles que se deslocam sem carro pela cidade e tem-se como resultado uma idade em que as zonas para pedestres existem por exclusão do espaço que não é ocupado por automóveis.

As aplicações de reformas infraestruturais nos espaços urbanos são desenvolvidas em regiões privilegiadas e, desta forma, acentua-se a desigualdade social. Atividades como o turismo são o exemplo mais evidente destes espaços em uso de forma produtiva, pois é nestes espaços que ocorre a vida em sociedade e as dinâmicas laborais. Essas estruturações consistem em ações políticas que atendem a conveniência do desenvolvimento da atividade turística para que esta seja vista como forma de solucionar os problemas locais. Os governos propalam o discurso do mercado neoliberal, ao afirmar ser o turismo o caminho para o desenvolvimento; de que é o caminho certo, pois não há outro; e que os obstáculos serão vencidos; omitindo-se da missão com que foi criado, de regular o mercado. O que se esperava do Estado democrático era a interlocução das críticas, sem ceder, facilmente, aos pontos de vistas da classe dominante. (TERENCIANO, 2018)

A participação dos habitantes na atividade turística na cidade do Rio de Janeiro é parte da função produtiva que esta cidade possui. Dessa forma Rolnik (1988) menciona a imagem da cidade como centro de produção e consumo e como permeia o imaginário a respeito da concepção citadina contemporânea. No entanto, além do olhar produtivo e econômico, é importante observar como tais espaços retorna aos cidadãos em forma de infraestrutura que possa fazer a inclusão de todos.

\section{TURISMO ACESSÍVEL NA CIDADE DO RIO DE JANEIRO}

A capital do estado do Rio de Janeiro, com população estimada em 6.718 .903 habitantes (IBGE, 2019), compõe a lista dos 10 destinos receptores mais procurados entre junho e julho de 2019 (BRASIL, 2020). A cidade mescla atividades nos espaços urbanos e em meio aos atrativos naturais, com expressiva importância econômica no cenário nacional no que tange ao turismo. Ela também está, segundo o Ministério do Turismo, está entre as cidades mais procuradas entre os turistas para férias (BRASIL, 2019).

A cidade do Rio de Janeiro, apesar da elevada participação da atividade turística na composição do PIB do estado (Riotur, 2019). A atividade do turismo depende de outros setores econômicos gerando impactos positivos e negativos na sociedade, também responsável por efeitos diretos e indiretos (BARRETTO, 2006, p. 72). Estes setores diretos e indiretos como transportes, hospedagens, alimentos e bebidas, fora os setores estruturais como segurança ou saúde são importantes para a atividade turística, pois um local estruturado constitui um local turisticamente confiável, seguro e recomendável. 
Os grandes eventos ali ocorridos - principalmente a Copa do Mundo (FIFA), em 2014, e os Jogos Olímpicos de 2016 - exigiram de seus gestores públicos investimentos para realizá-los e receber turistas de outras nacionalidades, implementando a infraestrutura urbana necessária.

Contudo, a necessidade de realizar adaptações dos locais turísticos da cidade do Rio de Janeiro fez com que as pessoas com deficiência se tornassem mais visíveis, principalmente após as obras para receber elevado fluxo de turistas com os grandes eventos. Como cidade turística que precisava se adaptar à demanda vindoura, houve uma preparação estrutural a fim de se ajustar, inclusive, para receber o público com deficiência. Com isto os equipamentos de uso para acessibilidade universal podem ser vistos em muitos lugares da cidade e há serviços públicos ou privados voltados ao uso da mesma, como as apresentadas nas figuras 01 e 02 (a seguir).

\section{QUADRO 01 - RAMPAS DE ACESSO A CADEIRANTES NA CIDADE DO RIO DE JANEIRO}

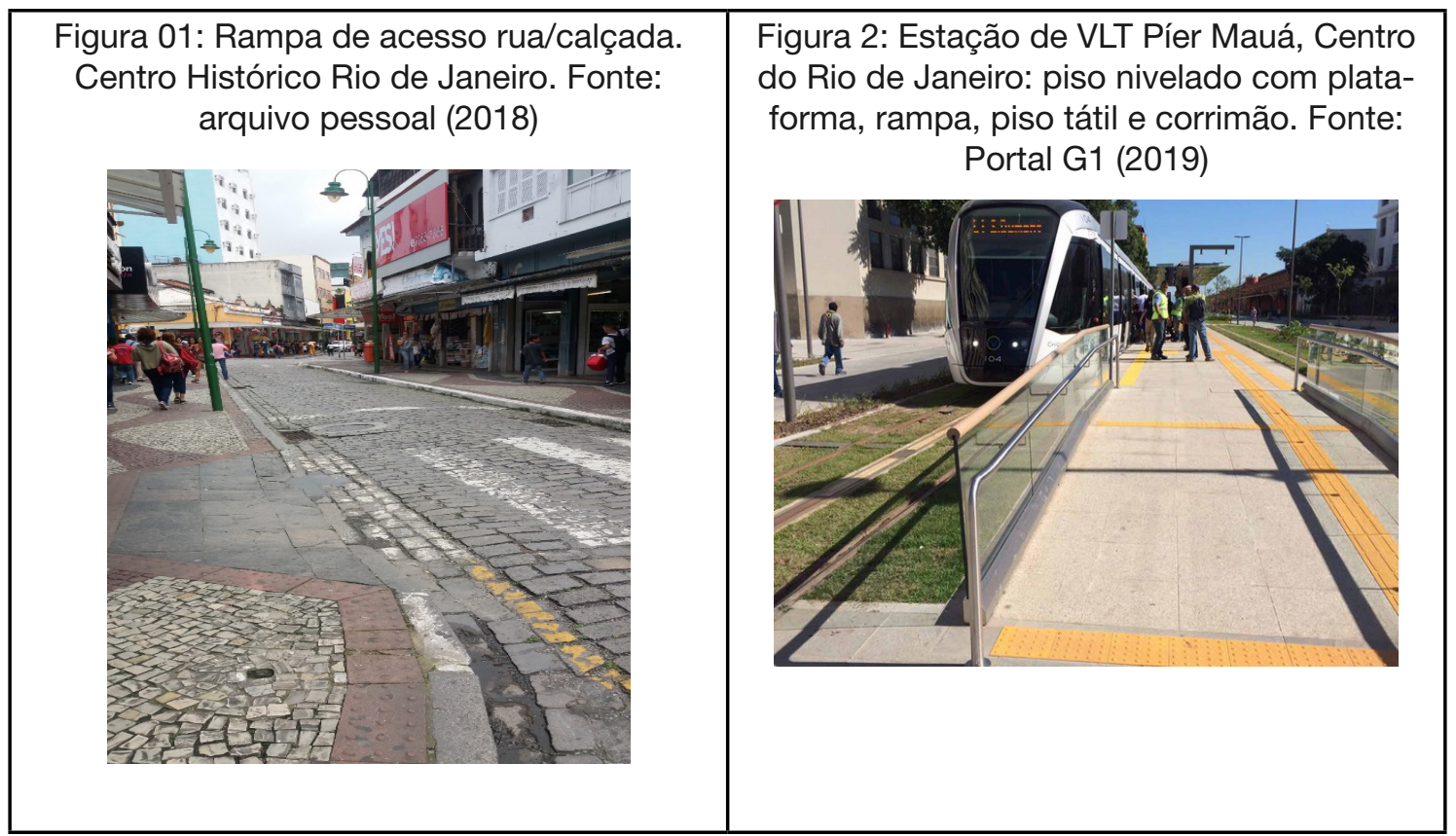

FONTE: As autoras (2020)

O portal eletrônico da empresa de turismo do município do Rio de Janeiro (RioTur) apresenta 57 atrativos turísticos na cidade do Rio de Janeiro. Dentre os atrativos, foram selecionados 17 que exemplificam estrutura de acessibilidade universal adequada à visitação para pessoas com deficiência e quais tipos de equipamentos existem nestes lugares. Os atrativos estão separados por categorias: museus/centro cultural, atrativos naturais e pontos turísticos, resumidos no quadro 02 na sequência. 
QUADRO 02 - ATRATIVOS TURÍSTICOS ACESSÍVEIS NA CIDADE DO RIO DE JANEIRO

\begin{tabular}{|c|c|c|c|c|}
\hline & $\begin{array}{l}\text { Ponto de } \\
\text { interesse } \\
\text { turístico }\end{array}$ & Localização & $\begin{array}{l}\text { Tipo de suporte/equipamento de } \\
\text { acessibilidade existente }\end{array}$ & $\begin{array}{l}\text { Adequado para } \\
\text { quais tipos de } \\
\text { deficiência }\end{array}$ \\
\hline \multirow{5}{*}{$\underset{\square}{\frac{1}{\pi}}$} & $\begin{array}{l}\text { Museu } \\
\text { Histórico } \\
\text { Nacional }\end{array}$ & Centro & $\begin{array}{l}\text { Banheiros adaptados } \\
\text { Equipamento móvel para colocar cadei- } \\
\text { ras de rodas e subir escadas }\end{array}$ & $\begin{array}{l}\text { Deficiência } \\
\text { motora }\end{array}$ \\
\hline & $\begin{array}{l}\text { Centro Cul- } \\
\text { tural Light }\end{array}$ & Centro & $\begin{array}{l}\text { Acessibilidade para pessoas com dificul- } \\
\text { dades de locomoção e cadeirantes } \\
\text { Rampas de acesso e banheiros adapta- } \\
\text { dos }\end{array}$ & $\begin{array}{l}\text { Deficiência } \\
\text { motora }\end{array}$ \\
\hline & $\begin{array}{l}\text { Centro Cul- } \\
\text { tural Banco } \\
\text { do Brasil }\end{array}$ & Centro & Elevadores & $\begin{array}{l}\text { Deficiência } \\
\text { motora }\end{array}$ \\
\hline & $\begin{array}{l}\text { Museu do } \\
\text { Amanhã }\end{array}$ & Centro & $\begin{array}{c}\text { Piso tátil / maquetes táteis } \\
\text { Banheiros adaptados } \\
\text { Elevadores } \\
\text { Rampas de acesso } \\
\text { Cadeiras de rodas }\end{array}$ & $\begin{array}{l}\text { Deficiência } \\
\text { visual e motora }\end{array}$ \\
\hline & $\begin{array}{l}\text { Museu de } \\
\text { Arte do Rio }\end{array}$ & Centro & $\begin{array}{l}\text { Banheiros adaptados } \\
\text { Elevadores } \\
\text { Rampas de acesso }\end{array}$ & $\begin{array}{l}\text { Deficiência } \\
\text { visual e motora }\end{array}$ \\
\hline \multirow{5}{*}{ 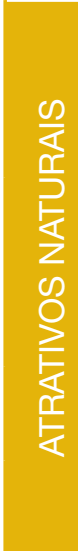 } & $\begin{array}{l}\text { Jardim } \\
\text { Botânico }\end{array}$ & Zona Sul & $\begin{array}{l}\text { Placas em braile no jardim sensorial } \\
\text { Piso tátil no jardim sensorial } \\
\text { Banheiros adaptados } \\
\text { Pavimentação lisa em alguns trechos }\end{array}$ & $\begin{array}{c}\text { Deficiência } \\
\text { visual e motora }\end{array}$ \\
\hline & $\begin{array}{l}\text { Praia de Co- } \\
\text { pacabana }\end{array}$ & Zona Sul & $\begin{array}{l}\text { Passarela emborrachada sobre a areia, } \\
\text { no posto } 5 \text {. }\end{array}$ & $\begin{array}{l}\text { Deficiência } \\
\text { motora }\end{array}$ \\
\hline & $\begin{array}{l}\text { Praia da Bar- } \\
\text { ra da Tijuca }\end{array}$ & Zona Oeste & Rampa de acesso no posto 3 da praia & $\begin{array}{l}\text { Deficiência } \\
\text { motora }\end{array}$ \\
\hline & $\begin{array}{l}\text { Floresta da } \\
\text { Tijuca }\end{array}$ & Zona Sul & $\begin{array}{l}\text { Trilha adaptada para pessoas com defi- } \\
\text { ciência }\end{array}$ & $\begin{array}{l}\text { Deficiência } \\
\text { motora }\end{array}$ \\
\hline & $\begin{array}{l}\text { Ilha de } \\
\text { Paquetá }\end{array}$ & Centro & Ruas planas, a maioria & $\begin{array}{l}\text { Deficiência } \\
\text { motora }\end{array}$ \\
\hline
\end{tabular}




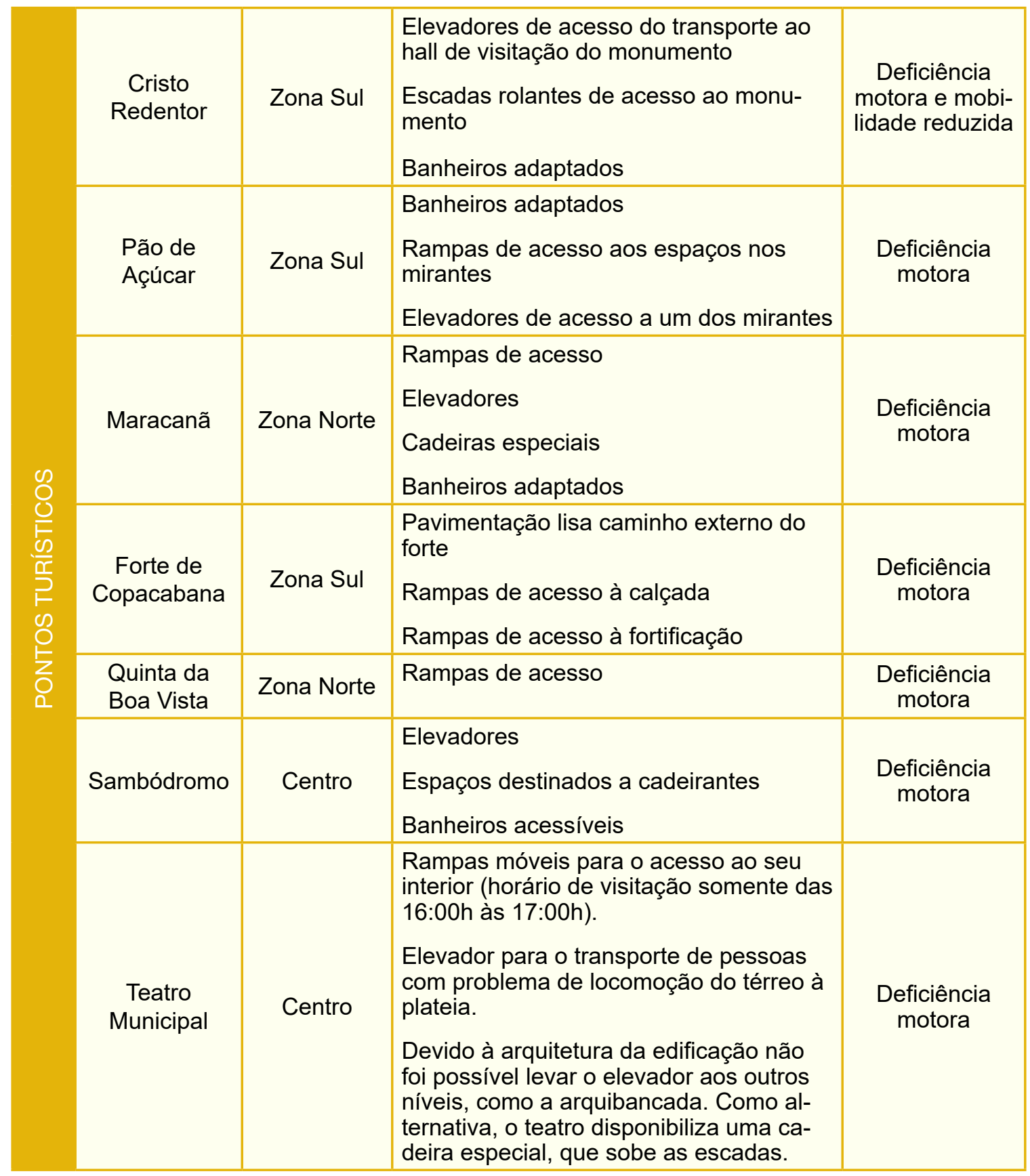

FONTE: Riotur (2019)

No quadro acima constam apenas os atrativos turísticos com estrutura de acessibilidade para pessoa com deficiência. Na página da Riotur identifica-se 57 atrativos, dos quais dezessete deles contam com estrutura de acessibilidade universal na cidade do Rio de Janeiro. Observa-se que a maioria dos locais carece de ajustes em sua infraestrutura e são necessários pela crescente demanda. É importante fomentar iniciativas que permitam à pessoa com deficiência ter condições de frequentar os espaços de lazer e que estes espaços estejam devidamente adequados para este público. 
Países de desenvolvimento econômico sensível às nuances do mercado e da política interna e externa como o Brasil, quando são responsáveis por algum evento local ou internacional de grande porte, encontram na atividade turística uma oportunidade de reestruturação local, pois, de certa forma, este evento representa uma motivação extra para a estruturação que o local precisa e, a partir destes eventos, há uma promessa de legado a ser deixado para a comunidade receptora. Este legado são as realizações, construções e melhorias deixadas para a(s) cidade(s) receptora(s) de turismo como uma herança que será desfrutada pela população local.

Mas para que esse legado se desenvolva na esfera que tange a acessibilidade, é importante o envolvimento do poder público. Logo, cabe, portanto, ao poder público liderar e motivar todas as iniciativas vinculadas ao desenvolvimento do desenho universal e assegurar o cumprimento da igualdade de direitos; sem deixar por isso de lado a responsabilidade que tem o setor privado de levar a cabo iniciativas que apoiem a melhora da acessibilidade nos âmbitos que lhes concerne (GARCIA, 2008, p. 55)

Desse modo, os grandes eventos esportivos deixaram um legado para a cidade do Rio de Janeiro em termos de acessibilidade urbana. Contudo, embora muitos locais já contem com estrutura acessível, demonstram uma falta de continuidade das vias acessíveis, não atendendo satisfatoriamente a demanda que se apresenta. Quanto a esse tema ainda há muito o que fazer, tendo em vista a necessidade de um planejamento adequado para desenvolvimento do turismo, tanto no sentido da sua otimização e melhoria dos serviços oferecidos, como em relação à preservação do patrimônio históricocultural, do ambiente natural, e das condições de qualidade de vida da população residente. (VARGAS, 1998)

No caso das Paraolimpíadas de 2016, em sua edição realizada na cidade do Rio de Janeiro, poucas iniciativas patrocinaram o evento, representando $7 \%$ de arrecadação a menos em relação a edição do evento realizado em Londres no ano de 2012 (REVISTA EXAME, 2016). Este fato evidencia a importância financeira acima do desenvolvimento social ou de qualquer legado voltado para a conscientização da sociedade a respeito da inclusão da pessoa com deficiência e de seu desenvolvimento através dos esportes.

Por outro lado, numa perspectiva neoliberal, a iniciativa privada investe nas pessoas com deficiência quando percebe uma oportunidade, inclusive cumprindo uma função que deveria ser do Estado. Nesse sentido pode-se destacar o Programa Praia Para Todos na cidade do Rio de Janeiro. Ele disponibiliza cadeiras anfíbias (Figura 03) e datas específicas em algumas praias da cidade a fim de integrar e socializar a pessoa com deficiência motora, a partir de dar uma oportunidade e de ter seu momento de lazer. 
FIGURA 3 - CADEIRAS ANFÍBIAS

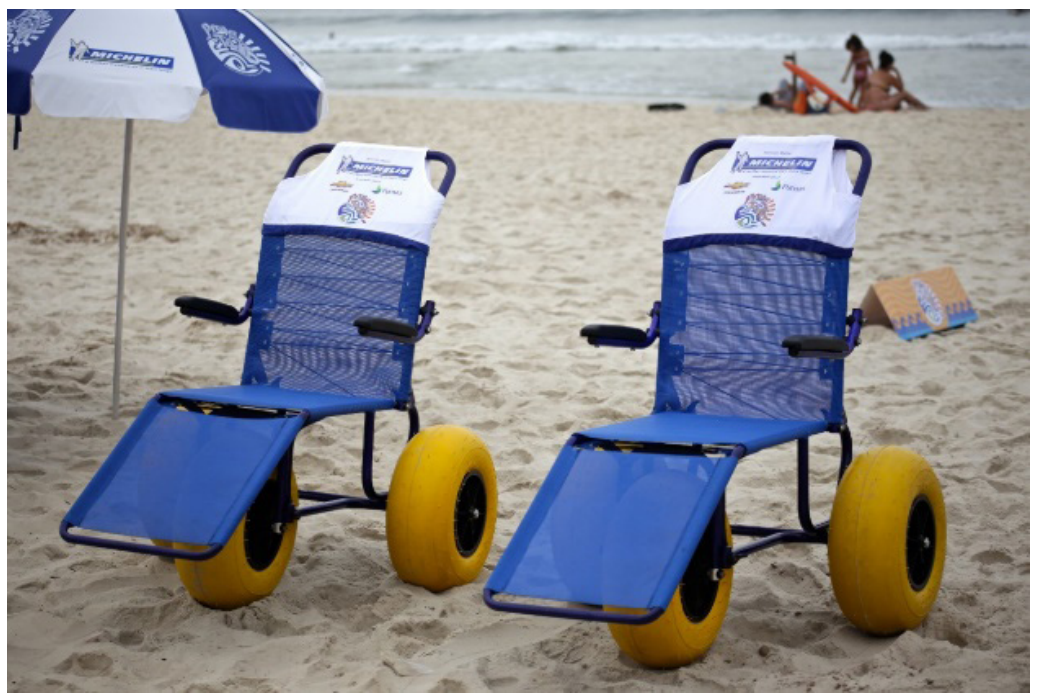

FONTE: Projeto Praia para Todos (2019)

O Projeto Praia para Todos possui atuação nas praias da Barra da Tijuca e na de Copacabana, tendo como objetivos promover a acessibilidade das praias cariocas às pessoas com deficiência ou com mobilidade reduzida de todas as idades.

A importância do projeto está pautada em fazer valer um direito da pessoa com deficiência que é o direito ao lazer. Além de uma premissa constitucional, também se trata de uma medida legal, pois a lei assegura os direitos à pessoa com deficiência e descreve o lazer como importante, conforme a Lei Federal $n^{\circ} 13146$, capítulo IX, artigo 42: "A pessoa com deficiência tem direito à cultura, ao esporte, ao turismo e ao lazer em igualdade de oportunidades com as demais pessoas, sendo-lhe garantido o acesso:

I - a bens culturais em formato acessível;

II - a programas de televisão, cinema, teatro e outras atividades culturais e desportivas em formato acessível;

III - a monumentos e locais de importância cultural e a espaços que ofereçam serviços ou eventos culturais e esportivos.

O projeto visa ainda oferecer inclusão social por meio de esporte e lazer, valorizar e incentivar a participação de familiares dos usuários, capacitar e formar equipes locais de profissionais especializados no atendimento à pessoa com deficiência no âmbito da saúde, do esporte e do lazer acessível. É preciso conscientizar a sociedade, os poderes públicos e empresários, sobre a necessidade de facilitar a vida das pessoas com deficiência de forma a exercerem sua cidadania, aumentar a autonomia por meio da prática para desportiva, bem como disseminar a cultura da valorização e do 
respeito à diversidade. Este projeto atendeu um público de 3.350 pessoas em 2018 (PROJETO PRAIA PARA TODOS, 2018).

Assim, a cidade do Rio de Janeiro, cujo título popular é o de "Cidade Maravilhosa", vive contradições. Apesar dos casos de corrupção na política, uma crise financeira já existente antes da pandemia de Covid-19. A atividade turística serve como chamariz financeiro para socorrê-la. Não apenas os megaeventos esportivos, mas outros como o Réveillon e o Carnaval motivam uma demanda em potencial de turistas na cidade do Rio de Janeiro. O carnaval deste ano (2020) na cidade registrou aumento de $31,2 \%$ se comparado ao mesmo período do ano passado (Riotur, 2020).

No entanto, para receber de forma adequada esta demanda, é importante o Estado pensar de que forma o local se apresenta - em termos de infraestrutura para que as pessoas se sintam à vontade em transitar por elas e, às pessoas com deficiência ou mobilidade reduzida, terem obstáculos minimizados.

\section{CONCLUSÃO}

A perspectiva neoliberal se revela seletiva em locais turísticos que carecem de adaptações para pessoas com deficiência motora, pois estes só serão inclusivos se o espaço tiver alguma utilidade em termos de negócio. No entanto, mesmo em locais turísticos de baixa demanda as adaptações das vias ou edificações não são adequadas ou não são suficientes, pois não são pensados para quem possui deficiência motora.

Este trabalho utilizou como base a forma como a cidade do Rio de Janeiro lida com a acessibilidade em seus locais turísticos. Foi importante observar em atividades de campo, na prática profissional de guiamento turístico, a diferença entre a expectativa e a realidade. Este estudo não considerou, por exemplo, meios de transporte ou qualidade das vias. Mas se tal estudo for desenvolvido, possivelmente haverá um parecer similar neste trabalho quanto a abordagem da questão da não continuidade, pois compreende-se que para chegar a um local, o entorno precisa estar pavimentado e estruturado para que as vias de locomoção estejam facilitadas.

Em função dos eventos esportivos a cidade do Rio de Janeiro foi motivada a repensar sua estruturação e, graças a isto, os modais de transportes contam com equipamentos voltados para a pessoa com deficiência que visam a flexibilidade na locomoção. No entanto, foi preciso que a cidade estivesse na eminência de receber um evento de grande porte para se adequar aos padrões da acessibilidade universal. Esta conveniência capital é o ponto discutido e mostrado nestas linhas que, diferente de outras cidades que se estruturam pensando em seus cidadãos em primeiro lugar, a cidade do Rio de Janeiro apenas apresentou melhorias quando um fator externo (evento) foi o motivador.

O desenvolvimento de uma atividade turística de qualidade está além das belezas que o local possui: está na dedicação da cidade a promover um ambiente inclusivo em funcionamento, que considera as necessidades de quem deveras necessita se locomover. 
Contudo, propõe-se que o turismo seja repensado de um ponto de vista além do capital: o ponto de vista da oportunidade de inclusão humana para que assim as cidades se tornem acolhedoras para seus cidadãos, em primeiro lugar e, finalmente, para o turista. Neste sentido a hospitalidade ao turista não se restringe apenas ao bom trato e a cortesia, mas é verificada no desenvolvimento de estruturas de adaptação onde o turista com deficiência motora seja bem recepcionado.

\section{REFERÊNCIAS}

BARRETTO, M. Manual de Iniciação ao Estudo do Turismo. Campinas, SP: Papirus, 2006. $160 \mathrm{p}$.

BOITO JR., A. As relações de classe na nova fase do neoliberalismo no Brasil. In: CAETANO, G.; MAYA, ML Sujetos sociales y nuevas formas de protesta en la historia reciente de América Latina. Buenos Aires: CLACSO Libros, 2006.

BORGES, C; AREIAS, K. As políticas públicas de lazer na mediação entre estado e sociedade: possibilidades e limitações. Revista Brasileira de Ciências do Esporte, v. 33, n. 3, p. 573-588, 2011.

BRASIL, Decreto-lei n 13.146, de 06 de julho de 2015. Institui a Lei Brasileira de Inclusão da pessoa Com Deficiência (Estatuto da Pessoa com Deficiência). Disponível em: http://www.planalto.gov.br/ccivil_03/_ato2015-2018/2015/lei/l13146. htm. Acesso em: 30 de mai. 2019.

BRASIL. Ministério do Turismo. Dados e Fatos. Disponível em: http://www. dadosefatos.turismo.gov.br/2016-02-04-11-54-03/demanda-tur\%C3\%ADsticainternacional/item/download/978_4b351c2bcd55475ce04611b7f5958bf0.html. Acesso em: 09 de setembro 2019.

BRASIL. Ministério do Turismo. Plano Nacional de Turismo 2018-2022. Disponível em: <http://www.turismo.gov.br/images/pdf/plano_nacional_2013.pdf >. Acesso em: 30 de maio 2019a.

BRASIL. Ministério do Turismo. Pesquisa inédita revela destinos brasileiros mais procurados em junho e julho. Disponível em http://www.turismo.gov. br/\%C3\%BAltimas-not\%C3\%ADcias/12751-pesquisa-do-mtur-revela-destinosbrasileiros-mais-procurados-em-junho-e-julho.html\#: :text=Fortaleza\%20 (CE)\%2C\%20Macei\%C3\%B3\%20(,f\%C3\%A9rias\%20de\%20junho\%20e\%20julho. Acesso em: 21 nov. 2020

COUTO, Cláudio G.; ABRUCIO, Fernando. O segundo governo FHC: coalizões, agendas e instituições. Tempo social, v. 15, n. 2, p. 269-301, 2003. 
FERNANDES, I. P.; COELHO, M. F. Economia do Turismo: Teoria e Prática. Rio de Janeiro. Elsevier, 2011.

FILGUEIRAS, L. O neoliberalismo no Brasil: estrutura, dinâmica e ajuste do modelo econômico. In: BASUALDO, E. M.; ARCEO, E. Neoliberalismo y sectores dominantes. Tendencias globales y experiencias nacionales. Buenos Aires: CLACSO (Consejo Latinoamericano de Ciencias Sociales), 2006.

GARCIA, C. C. Sociologia da Acessibilidade. Curitiba. IESDE BRASIL S. A, 2008.

GEHL, J. Cidades Para Pessoas. Anita Di Marco (trad.). 2 ed. São Paulo. Perspectiva, 2013.

INSTITUTO BRASILEIRO DE GEOGRAFIA E ESTATISTICA (IBGE), 2019. Disponível em: https://www.ibge.gov.br/cidades-e-estados/rj/rio-de-janeiro.html. Acesso em: 18 jul. 2020.

MENDES, B. C.; DE PAULA, N. M. A hospitalidade, o turismo e a inclusão social para cadeirantes. Revista Turismo em Análise, v. 19, n. 2, p. 329-343, 2008.

MOTTA BRANDAO, R. V. da. Ajuste Neoliberal no Brasil: Desnacionalização e Privatização do Sistema Bancário no Governo FHC (1995/2002). Tese (Doutorado em História Social) - Instituto de Ciências Humanas e Filosofia da Universidade Federal Fluminense. Rio de Janeiro, p. 391, 2003.

PROJETO PRAIA PARA TODOS. Disponível em: <http://www.praiaparatodos.com. br/>. Acesso em: 13 abr. 2019.

REVISTA EXAME. Patrocínio à Paraolimpíada foi tropeço do Rio-2016. São Paulo: Editora Abril, 2016. Disponível em <https://exame.abril.com.br/revistaexame/patrocinio-a-paralimpiada-foi-tropeco-do-rio-2016/>. Acesso em: 30 set. 2019.

RIBEIRO, L. C. Q. de. As metrópoles e o Direito à Cidade na Inflexão Ultraliberal da Ordem Urbana Brasileira. Texto para Discussão 012, Observatório das Metrópoles, 2020. Disponível em: <https://www.observatoriodasmetropoles.net.br/ wp-content/uploads/2020/01/TD-012-2020_Luiz-Cesar-Ribeiro_Final.pdf>. Acesso em: 17 jul. 2020.

EMPRESA DE TURISMO DO MUNICÍPIO DO RIO DE JANEIRO (RIOTUR). Atrativos turísticos. Disponível em: <http://www.rio.rj.gov.br/web/riotur/atracoes-turisticas>. Acesso em: 09 set. 2019. 
ROLNIK, R. O Que é Cidade. $1^{\text {a }}$ edição, 1988. São Paulo: Brasiliense, 2017.

TERENCIANO, F.; MUCACHE, C. R.; SALIÃO, A. Neoliberalismo e Percepções da Importância do Turismo em Moçambique: Uma Discussão Crítica e Prática. Turismo e Sociedade, v. 11, n. 1, p. 147-168, 2018.

VARGAS, H. C. Turismo e valorização do lugar. Revista Turismo em Análise, v. 9, n. 1, p. 7-19, 1998.

Recebido em: 01-10-2019.

Aprovado em: 05-12-2020. 
$S$ 